\title{
A Group of Klebsiella Mutants Showing Temperature- dependent Polysaccharide Synthesis
}

\author{
By MARY NORVAL AND I. W. SUTHERLAND \\ Department of General Microbiology, University of Edinburgh \\ College of Agriculture, West Mains Road, Edinburgh EH9 $3 \mathrm{JG}$
}

(Accepted for publication 25 April 1969)

\begin{abstract}
SUMMARY
Several mutants isolated from three Klebsiella aerogenes strains showed characteristics differentiating them from the wild type and also from the normal type of non-mucoid mutants. These mutants synthesize much less polysaccharide slime or capsule than the parent bacteria at low incubation temperature, but similar amounts at $37^{\circ}$. The colonies are of rough appearance at $20^{\circ}$ and liquid cultures at this temperature autoagglutinate. At $37^{\circ}$, mutant and parental types are indistinguishable. The mutants show altered phage sensitivity patterns at $20^{\circ}$ and the yield of lipopolysaccharide appears to be decreased at lower temperatures. Double mutants retaining certain of these characteristics but devoid of exopolysaccharide-synthesizing activity have also been isolated. The properties of the parent and mutant types are compared.
\end{abstract}

\section{INTRODUCTION}

In studies on polysaccharide biosynthesis, frequent use has been made of mutants unable to synthesize the exopolysaccharide slime or capsule characteristic of the parent organism, for example, Diplococcus pneumoniae capsular polysaccharide (Smith, Mills \& Harper, I957), the slime polysaccharide synthesized by Escherichia strains and by other species of the Enterobacteriaceae (Beiser \& Davis, 1957). During studies on exopolysaccharide biosynthesis by strains of Klebsiella aerogenes a number of mutants differing from normal non-mucoid variants were isolated. The unusual properties of these mutants and their relationship to the parent strains are reported.

\section{METHODS}

Bacteria and methods of culture. Three strains of Klebsiella aerogenes have been used. Strains A 3(SL) and A4 are laboratory strains used in several earlier studies (Wilkinson, Dudman \& Aspinall, 1955; Sutherland, 1967). Strain w70 was kindly provided by Dr D. G. McPhee, School of Biological Sciences, University of East Anglia. Strains KPI and A4-O are non-mucoid mutants of A3(SL) and A4, respectively, and are included in certain experiments for comparison. All strains were cultured routinely on nutrient agar at $35^{\circ}$. For production of extracellular polysaccharide, strains were grown on a solid nitrogen-deficient medium (Sutherland \& Wilkinson, 1965). A liquid version of this medium was also used for some experiments. The minimal medium used was that described by Davis \& Mingioli (1950). Liquid cultures were grown in Erlenmeyer flasks containing half the nominal volume and shaken at 200-300 rev./min. in an orbital incubator. Initial isolation of mutants was made on 
eosin methylene blue (EMB) agar with glucose as carbon source or on nitrogendeficient medium.

Bacteriophages. The phages having Klebsiella aerogenes A3 (SL) as host have been described earlier (Sutherland, 1967). Bacteriophage active against other $K$. aerogenes strains were isolated from raw sewage by the same techniques except that membrane filtration and not chloroform was used to remove bacteria from the preparations. The phage-induced fucosidase preparation was that used by Sutherland (1967).

Mutagenesis. 'Old cultures' were nutrient-broth tube cultures held at $35^{\circ}$ for to to 20 days. Dilutions were made into sterile $0.9 \%(\mathrm{w} / \mathrm{v})$ saline and $0 . \mathrm{I} \mathrm{ml}$. samples were spread over the surface of suitable solid media. 2-Aminopurine mutagenesis was performed on overnight nutrient broth cultures which were diluted to approximately $\mathrm{IO}^{4}$ bacteria/ml. in broth containing 2-aminopurine $(200 \mu \mathrm{g}$. $/ \mathrm{ml}$.), and incubated $48 \mathrm{hr}$ at $35^{\circ}$. Samples were then spread over nitrogen-deficient solid medium.

Preparation of polysaccharides and lipopolysaccharides. The exopolysaccharides produced by the three strains were of two types: slime or capsule. These were isolated and purified by the techniques originally described by Wilkinson et al. (1955). Lipopolysaccharides were extracted from lyophilized bacterial cells by the phenol + water method using a 5 min. extraction time (Lüderitz et al. 1965). After removal of the phenol by dialysis, the extracts were concentrated under reduced pressure and the lipopolysaccharide was freed from other material by ultracentrifugation at $100,000 \mathrm{~g}$ for $4 \mathrm{hr}$, then lyophilised. The supernatant fluid was also freezedried and assayed for glucose as a measure of glycogen.

Microanalysis. The constituent sugars of the polysacharides and lipopolysaccharides were identified by paper chromatography in the solvent of Fischer \& Dörfel (I955), after hydrolysis in $\mathrm{N}_{-} \mathrm{H}_{2} \mathrm{SO}_{4}$. The individual sugars were determined as described previously (Sutherland, 1967). In addition, mannose was determined by the cysteine + sulphuric acid assay (Dische, Shettles \& Osnos, 1949) and total polysaccharide by the anthrone method. The $O$-acetyl groups found in two of the three exopolysaccharides were estimated by the hydroxylamine-ferric chloride assay (Hestrin, 1949). Total protein was assayed by the Folin technique. All colorimetric results were read in glass cells in a Zeiss PMQII spectrophotometer or a Unicam SP 500 instrument. These were also used for determining the turbidity of cell suspensions and for enzyme assays.

Paper chromatography and paper electrophoresis. Paper chromatograms on Whatman no. I paper were run in ethyl acetate + acetic acid + pyridine + water $(5+I+5+3$, by vol.) (Fischer \& Dörfel, 1955) or ethyl acetate + acetic acid +formic acid + water $(\mathrm{I} 8+3+\mathrm{I}+4$, by vol.) (Feather \& Whistler, I962) for 24 or $40 \mathrm{hr}$ respectively. Partial acid hydrolysates $\left(\mathrm{N}-\mathrm{H}_{2} \mathrm{SO}_{4}\right.$ for $15 \mathrm{~min}$. at $100^{\circ}$.) were neutralized with $\mathrm{Ba}(\mathrm{OH})_{2}$ solution and compared by paper electrophoresis in pyridinium acetate at $\mathrm{pH} \mathrm{5.3}$ using the conditions previously described (Sutherland \& Wilkinson, I968), and by paper chromatography in the acid solvent.

\section{RESULTS}

\section{Isolation of colonies with crenated colony type (CR mutants).}

The parent strains were subjected to mutagenesis and spread, after expression of mutations, on nitrogen-deficient or EMB medium and the colonies examined for the presence of non-mucoid types ( $O$ mutants). These occurred at low frequency and were 
slightly smaller than the wild-type colonies, lacking the mucoidness and consequent glossy appearance. The non-mucoid cells grew in liquid culture with uniform turbidity and had a growth rate similar to the parental type. Several hundred $O$ mutants have been isolated using various mutagens. During examination of colonies following mutagenesis, another type of mutant was observed. These colonies (CR mutants) were detected on plates incubated at $30^{\circ}$ or $20^{\circ}$ and had a very characteristic appearance. They were of the same size as those of non-mucoid mutants (Io to $12 \mathrm{~mm}$. diam. after $48 \mathrm{hr}$ growth on nutrient agar at $20^{\circ}$ ). The outline of the colonies was irregular and the consistency more friable than either the parental or $\mathrm{O}$ type, and ridges radiated from a central apex. The CR mutants were only isolated following treatment with aminopurine and not with other mutagens. One CR mutant was obtained as a spontaneous mutant from an 'old culture'. From two of the CR mutants further mutagenesis with aminopurine led to the isolation of another form which we have designated CR-O mutants. These cultures possessed properties common to $\mathrm{CR}$ mutants and $\mathrm{O}$ mutants. The derivation of mutants and their type is shown in Table I. The frequency of occurrence of either CR or CR-O mutants was very much lower than that of the O mutants when aminopurine was used as mutagen. Attempts to derive a CR-O mutant from Klebsiella aerogenes $\mathrm{w} 70$ have been unsuccessful.

Table I. The type and mode of isolation of the mutants used in the present study

$\begin{array}{llll}\text { Parent } & \text { Mutant } & \text { Type } & \begin{array}{c}\text { Mutagen } \\ \text { A 3(SL) }\end{array} \\ \text { A 3-CR } & \text { CR } & \text { 2-Aminopurine } \\ \text { A 3-CR } & \text { A 3-CRO } & \text { CR-O } & \text { 2-Aminopurine } \\ \text { W70 } & \text { w70-CR I } & \text { CR } & \text { 2-Aminopurine } \\ \text { W70 } & \text { w70-CR 2 } & \text { CR } & \text { 2-Spontaneous } \\ \text { A4 } & \text { A4-CR } & \text { CR } & \text { 2-Aminopurine } \\ \text { A4-CR } & \text { A4-CRO } & \text { CR-O } & \text { 2-Aminopurine }\end{array}$

\section{Cultural characteristics of $C R$ mutants}

The characteristic colonial appearance of CR mutants on solid media was only observed following incubation at 20 to $30^{\circ}$ for 24 to $48 \mathrm{hr}$. After longer incubation at these temperatures some mucoidness was noticed. The colonies also become less friable and very adhesive to the medium. Incubation at $37^{\circ}$ led to cultures almost indistinguishable from the wild-type strains. The CR-O mutants were recognizable as their characteristic colonial appearance was retained on incubation at $37^{\circ}$. They thus appeared to lack the ability to synthesise extracellular polysaccharide, so resembling $\mathrm{O}$ mutants. Colonies on solid media were very friable.

Liquid cultures of $\mathrm{CR}$ mutants at $20^{\circ}$ in all the media tested underwent autoagglutination and sedimentation as a granular aggregate of bacteria. At $37^{\circ}$ liquid cultures were indistinguishable from the wild type, being turbid and viscous due to polysaccharide excretion. The CR-O mutants showed the same autoagglutination and lack of polysaccharide production at all incubation temperatures. The autoagglutination of CR or CR-O mutants in liquid defined media was unaffected by altering the concentration of $\mathrm{Ca}^{2+}$ or $\mathrm{Mg}^{2+}$ ions between 0 and $0.5 \mathrm{mM}$ and by the addition of EDTA up to $3 \mathrm{mg} / \mathrm{ml}$. (w/v). Addition of Tween 80 in concentrations up to $\mathrm{r} \%(\mathrm{w} / \mathrm{v})$ also failed to prevent autoagglutination. All strains grew in the same manner using glucose, galactose, mannose or glycerol as carbon and energy source in defined media. 


\section{Reversion}

A marked difference between $\mathrm{CR}$ and $\mathrm{O}$ mutants was in the stability of the mutation. In the Klebsiella aerogenes A4-O and other non-mucoid variants spontaneous revertants were never detected despite examination of more than 10,000 colonies. Application of various mutagens did not induce reversion. The same was true of the CR-O mutants. However the CR mutants reverted to the parental type with varying frequencies. Thus A3-CR reverted to A3(SL) spontaneously with $0.01 \%$ frequency, whereas no spontaneous revertants from A4-CR were observed. The use of acriflavin, 2-aminopurine or ethanemethanesulphonate resulted in a reversion frequency of $0.3 \%$ to $0.4 \%$ in the mutant A4-CR. Lower frequencies were observed using other mutagens. The mutants from $\mathrm{w} 70$ behaved similarly.

\section{Table 2. The composition of slime and capsule exopolysaccharides}

\begin{tabular}{llllc} 
Strain & \multicolumn{1}{c}{ Type } & $\begin{array}{c}\text { Growth } \\
\text { temperature }\end{array}$ & \multicolumn{1}{c}{ Constituents } & $\begin{array}{c}\text { Molar ratio } \\
\text { (approx.) }\end{array}$ \\
A4 & Capsule, slime & All & Glc:Gal:GlcUA & I:2:I \\
A4-CR & Capsule, slime & 30 to $35^{\circ}$ & Glc:Gal:GllcUA & I:2:I \\
A3(S I) & Slime & All & Glc:Fuc:GlcUA:acetyl & $4: 2: 2: 1$ \\
A 3-CR & Slime & 30 to $35^{\circ}$ & Glc:Fuc:GlcUA:acetyl & $4: 2: 2:$ I \\
w70 & Capsule, slime & All & Gal:Mann:GlcUA:acetyl & I:I:I:I \\
w70-CR2 & Capsule, slime & 30 to $35^{\circ}$ & Gal:Mann:GlcUA:acetyl & I:I:I:I
\end{tabular}

\section{Exopolysaccharide synthesis}

It was obvious during the initial examination of cultures that differences in exopolysaccharide synthesis occurred between parent and CR strains. It was thus possible that the mutants might synthesize polysaccharides of altered composition and structure. The repeating unit of Klebsiella aerogenes A 3(SL) slime polysaccharide has already been identified (Sutherland, 1967; Sutherland \& Wilkinson, 1968). Hydrolysates of A4 polysaccharide contained glucose, galactose and glucuronic acid, while acetyl and pyruvoyl groups were absent. The capsular polysaccharide of strain $\mathrm{w} 70$ contained galactose, mannose, glucuronic acid and $O$-acetyl groups. The composition and approximate molar ratios of the polysaccharides are shown in Table 2 together with the composition of the material secreted by the three corresponding CR mutants when grown at $35^{\circ}$. The parent and mutant strains secrete polysaccharides of the same chemotype with sugars present in the same molar ratio. Further proof of the similarity of the pairs of polysaccharides was obtained by comparison of partial acid hydrolysates by paper electrophoresis and paper chromatography. The fragments obtained were identical for each parent and mutant strain. In addition, phage-induced fucosidases active against A3(SL) polysaccharide yielded the same hydrolysis products from A 3 (SL) and A3-CR polysaccharides.

On nitrogen-limited defined media with glucose as carbon and energy source, the production of polysaccharide was determined after separation from cells by the anthrone technique. The slime or capsular material was removed by boiling and the bacterial deposits by centrifugation. For all the strains examined, the greatest differences between parent and mutant strains were observed at $20^{\circ}$ at which temperature the CR mutants produced only about $30 \%$ that excreted by the parent in liquid medium. Similar results were obtained for each set of mutants and values for A4, A4-CR and 
A4-CRO are given in Table 3. The CR-O mutants produced no polysaccharide detectable by the techniques used, and so resemble $O$ mutants.

\section{Lipopolysaccharides and glycogen}

The occurrence of autoagglutination and 'roughness' in other species of Enterobacteriaceae in usually associated with the production of incomplete lipopolysaccharides (Lüderitz, Staub \& Westphal, I966). Thus examination of the mutant lipopolysaccharides might reveal loss of part of the macromolecule. An earlier study of the A3 and A4 strains showed that they contained 17 to $23 \%$ galactose but;only $2 \%$ glucose (Sutherland \& Wilkinson, I966). They thus differed from the types of polymer common to members of the genera Salmonella, Shigella and Escherichia, which all

Table 3. Exopolysaccharide production on nitrogen-limited media

\begin{tabular}{|c|c|c|c|c|c|c|c|c|c|}
\hline \multirow[b]{3}{*}{ Strain } & \multirow[b]{3}{*}{ Medium } & \multicolumn{8}{|c|}{ Incubation temperature } \\
\hline & & \multicolumn{3}{|c|}{$35^{\circ}$} & \multicolumn{3}{|c|}{$30^{\circ}$} & \multicolumn{2}{|c|}{$20^{\circ}$} \\
\hline & & $24 \mathrm{hr}$ & $48 \mathrm{hr}$ & $72 \mathrm{hr}$ & $48 \mathrm{hr}$ & $72 \mathrm{hr}$ & $96 \mathrm{hr}$ & $72 \mathrm{hr}$ & $96 \mathrm{hr}$ \\
\hline \multirow[t]{2}{*}{ A4 } & Solid & $2 \cdot 8$ & 3.5 & $3 \cdot 0$ & $\mathbf{I} \cdot 6$ & $2 \cdot 0$ & $2 \cdot 8$ & $3 \cdot 7$ & $3 \cdot 7$ \\
\hline & Liquid & $2 \cdot I$ & $2 \cdot 3$ & $2 \cdot 4$ & $2 \cdot I$ & $I \cdot 9$ & $2 \cdot 0$ & $\mathbf{2} \cdot 2$ & $2 \cdot 2$ \\
\hline \multirow[t]{2}{*}{ A4-CR } & Solid & $3 \cdot 3$ & $2 \cdot I$ & $2 \cdot 6$ & $I \cdot 4$ & $2 \cdot 0$ & $2 \cdot 5$ & $I \cdot O$ & 0.9 \\
\hline & Liquid & $2 \cdot 9$ & $2 \cdot 0$ & $2 \cdot I$ & $1 \cdot 8$ & $2 \cdot 0$ & $2 \cdot 6$ & $I \cdot 2$ & $\mathbf{I} \cdot \mathbf{I}$ \\
\hline A4-CRO & $\begin{array}{c}\text { Solid or } \\
\text { liquid }\end{array}$ & 0.1 & $0 \cdot I$ & 0.1 & 0.1 & 0.05 & 0.05 & 0.05 & 0.05 \\
\hline
\end{tabular}

All values are given as $\mathrm{mg}$. polysaccharide (glucose anthrone value)/mg. cell protein.

Table 4. The yield of lipopolysaccharides by $C R$ and $C R-O$ strains

\begin{tabular}{|c|c|c|c|c|c|}
\hline \multirow[b]{2}{*}{ Strain } & \multirow[b]{2}{*}{$\begin{array}{c}\text { Growth } \\
\text { temperature }\end{array}$} & \multirow[b]{2}{*}{$\begin{array}{l}\text { Lipopoly- } \\
\text { saccharide } \\
\text { (\% dry cells) }\end{array}$} & \multicolumn{3}{|c|}{ Lipopolysaccharide } \\
\hline & & & Glucose & $\begin{array}{l}\text { Composition } \\
\text { galactose }\end{array}$ & $\begin{array}{c}\text { Glycogen } \\
\text { (\% dry } \\
\text { cells)* }\end{array}$ \\
\hline A 3-CRO & $\begin{array}{l}20^{\circ} \\
35^{\circ}\end{array}$ & $\begin{array}{l}1 \cdot 10 \\
3 \cdot 10\end{array}$ & $\begin{array}{l}2 \cdot 4 \\
I \cdot 2\end{array}$ & $\begin{array}{l}19.0 \\
15.0\end{array}$ & $\begin{array}{l}2 \cdot 2 \\
5.5\end{array}$ \\
\hline W 70-CR 2 & $\begin{array}{l}20^{\circ} \\
35^{\circ}\end{array}$ & $\begin{array}{l}1.45 \\
5.09\end{array}$ & $\begin{array}{l}I \cdot I \\
I \cdot 0\end{array}$ & $\begin{array}{l}14 \cdot 0 \\
16 \cdot 3\end{array}$ & $\begin{array}{l}2 \cdot 8 \\
1 \cdot 0\end{array}$ \\
\hline A4-CRO & $\begin{array}{l}20^{\circ} \\
35^{\circ}\end{array}$ & $\begin{array}{l}2 \cdot 57 \\
3 \cdot 33\end{array}$ & $\begin{array}{l}I \cdot 6 \\
1 \cdot 2\end{array}$ & $\begin{array}{l}17 \cdot 9 \\
18 \cdot 6\end{array}$ & $\begin{array}{l}5.4 \\
1 \cdot 9\end{array}$ \\
\hline A4-CR & $\begin{array}{l}20^{\circ} \\
35^{\circ}\end{array}$ & $\begin{array}{l}I \cdot 2 \\
2 \cdot 1\end{array}$ & $\begin{array}{l}2 \cdot 5 \\
3 \cdot 7\end{array}$ & $\begin{array}{l}22 \cdot 5 \\
20 \cdot 7\end{array}$ & $\begin{array}{l}6.6 \\
6.0\end{array}$ \\
\hline
\end{tabular}

* The values for glycogen were derived by multiplying the glucose content of the ultracentrifuge supernatants by the weight of dry material.

contain approximately equal quantities of glucose and galactose in their basal structures (Lïderitz et al. 1966). The galactan nature of the lipopolysaccharide of Klebsiella A3(sL) and another strain has been confirmed by structural studies (Koeltzow, Epley \& Conrad, I968). Strain w70 also proved to have a similar lipopolysaccharide. 
Several of the CR and CR-O strains were grown in nutrient broth containing $1 \%(w / v)$ glucose in shaken culture at $20^{\circ}$ or $35^{\circ}$. The bacteria were harvested by centrifugation, washed and lyophilized. The yields of lipopolysaccharide extracted by phenol/ water and purified by ultracentrifugation are shown in Table 4 . It can be seen that the polymer yields were generally lower following incubation at $20^{\circ}$ than those from $35^{\circ}$. The composition of the macromolecules as measured by their glucose and galactose contents appeared to be constant. The yields of glycogen varied considerably and do not show any distinct pattern.

\section{Phage sensitivity}

One of the methods used to check the identity of mutants with the wild type was to test the sensitivity of both strains to one or more bacteriophages. The bacterial culture was incubated in nutrient broth then spread over the surface of plates of nutrient agar. These were allowed to dry at room temperature for $30 \mathrm{~min}$. Drops $\left(0.02 \mathrm{ml}\right.$.) of bacteriophage suspensions containing approximately $10^{6}$ plaque-forming units were applied and incubation continued at varying temperatures. Initial tests showed no difference in phage sensitivity after incubation at $20^{\circ}$ or $37^{\circ}$. When, however, the parent cells were incubated through two subcultures in nutrient broth at $20^{\circ}$ then used to seed the plate, there were several differences from the sensitivity pattern observed at $37^{\circ}$. These results are shown in Table 5 . It seems probable that in

Table 5. Phage sensitivity patterns of mutant and wild-type strains

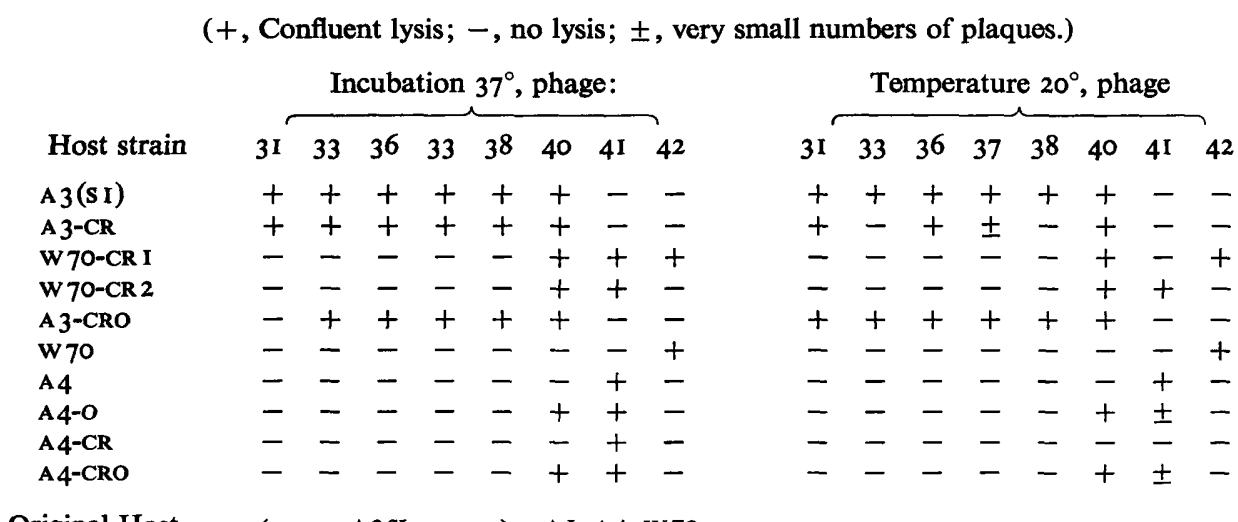

Original Host $\leftarrow$ A3SL $\rightarrow$ A I A4 W70

certain of the mutants the phage receptor is no longer synthesized at the lower temperature or alternatively the mutants are unable to liberate mature phage. If the defect is one of surface properties it is presumably due to a loss of carbohydrate metabolism at a step which is also essential for exopolysaccharide synthesis. Thus strain A3-CR was no longer susceptible to phages $F_{33}$ and 38 , which both acted on the parent and on A3-CR at $37^{\circ}$. It is interesting that in some cases the mutants are susceptible to more phages than the mucoid parent. This is presumably due to occlusion of the bacterial surface by the capsule preventing phage uptake as it is not seen in the $\mathrm{A}_{3}$ mutants where the parent strain produces slime only. 


\section{DISCUSSION}

Mutations involving exopolysaccharide biosynthesis in Klebsiella aerogenes appear to occur in two ways. The wild-type organisms producing capsules and slime may undergo a mutation causing loss of the ability to form a discrete capsule. Such a slime-forming (sL type) mutants are exemplified by $K$. aerogenes A 3 (SL) which secretes an exopolysaccharide identical in all respects tested with the capsular polysaccharide synthesized by the parent cells (Dudman \& Wilkinson, 1956). Either the wild type or the sL type can undergo a mutation causing complete loss of polysaccharide-synthesizing capacity. Such non-mucoid $(O)$ mutants show no tendency to revert. Attempts to render them mucoid by transduction were unsuccessful, although other markers were transferred (McPhee, Sutherland \& Wilkinson, 1969). Such O mutants deficient in precursor-synthesizing or transferase activity are analagous to many of the mutants isolated during studies on lipopolysaccharide biosynthesis (Lüderitz et al. 1966). Due to the lack of suitable selection procedures no mutants synthesizing in complete exopolysaccharide have yet been identified. Indeed by virtue of their repeating unit structure it is probable that the mutation is an 'all or none' phenomenon causing complete loss of polysaccharide-synthesizing capability. Nothing analagous to the 'rough' mutants isolated in studies on lipopolysaccharide biosynthesis has yet been found in exopolysaccharide studies.

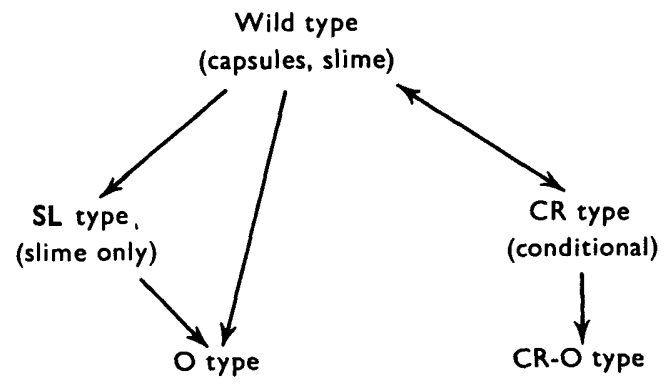

Fig. I. Scheme for mutations involving polysaccharide synthesis in the genus Klebsiella.

The second and apparently unusual form of mutation is that involved in CR mutants. These apparently only arise spontaneously or under the influence of aminopurine. CR clones appear to be much less stable than $\mathrm{O}$ mutants. Further mutagenesis can, albeit rarely, lead to isolation of a double mutant retaining the characteristic colonial morphology of the CR mutant but having completely lost exopolysaccharidesynthesizing capacity even at $37^{\circ}$. The scheme involving such mutations is shown in Fig. I. The CR mutants are obviously conditional mutants and are unusual in that the mutation appears to have two distinct effects, assuming that no double mutation has occurred. The first effect is on exopolysaccharide synthesis, which is greatly reduced by lower incubation temperature but returns to the level of the wild type on temperature up-shift. The second effect is on one of the surface components of the bacterial cells, apparently the lipopolysaccharide. This effect appears to be a quantitative one rather than an alteration to the lipopolysaccharide structure. A consequence of the lower lipopolysaccharide content is the agglutinability and 'roughness' of the cultures. These 
observed results from the conditional mutation are consistent with an alteration to an enzyme involved in the formation of nucleotide precursors for the lipopolysaccharide and the exopolysaccharide or alternatively an altered regulator. The lipopolysaccharides of the Klebsiella strains used in this study contain galactose, heptose, 2-ketodeoxyoctonic acid and $N$-acetylglucosamine (Sutherland \& Wilkinson, 1965). The sugars found in the slime or capsular polysaccharides are fucose, glucose, galactose glucuronic acid and mannose. Thus galactose is the only sugar common to both lipopolysaccharide and exopolysaccharide, but only in strains A4 and W70, not in A 3(SL). We therefore conclude that the mutation occurs in the sequence of reactions.

$$
\text { glucose } \rightarrow \text { glucose-6-phosphate } \rightarrow \text { glucose-1-phosphate } \rightarrow \text { UDP-glucose }
$$

Alteration in any of the three enzymes involved, hexokinase, phosphoglucomutase or UDP-Glc pyrophosphorylase would affect either polymer if UDP-Glc is the glucosyl donor involved in exopolysaccharide biosynthesis. The results for glycogen yields were not consistent enough to determine whether a significant reduction had occurred at lower temperatures. The donor for glycogen synthesis being ADP-glucose (Gahan \& Conrad, 1968), a reduction in glycogen would favour the first two enyzmes in the sequence as the possible sites of mutation. One similar conditional alteration in surface property involving what is also probably a polysaccharide, has been reported (Knolle \& Ørskov, 1967). The $\mathrm{f}^{+}$antigen of Escherichia coli is lost at lowered incubation temperature but is again formed on return of the cells to $37^{\circ}$.

Further experiments to identify the enzyme involved in the ' $C R$ ' conditional mutation of Klebsiella aerogenes strains are proceeding.

The authors are grateful to Miss I. C. Miller for technical assistance and to the Science Research Council for financial support.

\section{REFERENCES}

BeISER, S. M. \& DAVIS, B. D. (1957). Mucoid mutants of Escherichia coli. J. Bact. 74, 303.

DAvIs, B. D. \& Mingroli, E. D. (1950). Mutants of Escherichia coli, requiring methionine or vitamin $\mathrm{B}_{12}$. J. Bact. 60, 17.

Dische, Z., Shetrles, L. B. \& Osnos, M. (1949). Now specific colour reactions of hexoses and spectrophotometric micromethods for their determination. Archs Biochem. Biophys. 22, 169.

Dudman, W. F. \& WIIKInson, J. F. (1956). The composition of the extracellular polysaccharide of Aerobacter-Klebsiella strains. Biochem. J. 62, 289.

FEATHER, M.S. \& WHISTLER, R. L. (1962). Isolation and characterisation of the principle hemicellulose from corn germ. Archs. Biochem. Biophys. 98, II 1.

FISCHER, F. G. \& DöRFrL, H. (I955). Die papier-chromatographische Trennung und Bestimmung der Uronsauren. Hoppe-Seyler's Z. physiol. Chem. 301, 224.

GahaN, L. C. \& ConRAD, H. E. (1968). An enzyme system for de novo biosynthesis of glycogen in Aerobacter aerogenes. Biochemistry, N.Y. 7, 3979.

Hestrin, S. (1949). The reaction of acetylcholine and other carboxylic acid derivatives with hydroxylamine and its analytical application J. biol. Chem. r80, 249.

KNOLLe, P. \& Ørskov, I. (1967). The identity of the $\mathrm{f}^{+}$antigen and the cellular receptor for the RNA phage fr. Molec. Gen. Genetics 99, I09.

Koeltzow, D. E., Epley, J. D. \& Conrad, H. E. (1968). The lipopolysaccharides of Aerobacter aerogeones strains A3(SL) and NCTC243. Biochemistry, N.Y. 7, 2920.

LÜDerrtz, O., Staub, A. M. \& WestPhal, O. (1966). Immunochemistry of $O$ and $R$ antigens of Salmonella and related Enterobacteriaceac. Bact. Rev. 30, 192. 
Lüderitz, O., Risse, H. J., Shulte-Holthausen, H., Strominger, J. L., Sutherland, I. W. \& WeSTPHAL, O. (1965). Biochemical studies of the smooth-rough mutation in Salmonella minnesota. J. Bact. 89, 343.

McPheE, D. G., Sutherland, I. W. \& Wilkinson, J. F. (1969). Transduction in Klebsiella. Nature, Lond. 221, 475 .

Smith, E. E., Mills, G. T. \& Harper, E. M. (1957). A comparison of the uridine pyrophosphoglycosyl metabolism of capsulated and non-capsulated pneumococci. J. gen. Microbiol. 16, 426.

SUTHERLAND, I. W. (1967). Phage-induced fucosidases hydrolysing the exopolysaccharide of Klebsiella aerogenes type 54 [A 3(sL)]. Biochem. J. 104, 278.

SutherLand, I. W. \& WilkINson, J. F. (1965). Depolymerases for bacterial exopolysaccharides obtained from phage-infected bacteria. J. gen. Microbiol. 39, 383.

SutHeRLAND, I. W. \& Wirkinson, J. F. (1966). The composition of lipopolysaccharides of Klebsiella aerogenes and Aerobacter cloacae. Biochim. biophys. Acta I17, 26I.

SUtherLAND, I. W. \& WiLKInson, J. F. (I968). The exopolysaccharide of Klebsiella aerogenes A 3(sL) (type 54). Biochem. J. 1ro, 749.

Wilkinson, J. F., Dudman, W. F. \& Aspinall, G. O. (1955). The extracellular polysaccharide of Aerobacter aerogenes A 3(sL) (Klebsiella type 54). Biochem. J. 59, 446. 